\title{
Microtubule heterogeneity of Ornithogalum umbellatum ovary epidermal cells: non-stable cortical microtubules and stable lipotubuloid microtubules
}

\author{
Maria Kwiatkowska, Dariusz Stępiński, Justyna T. Polit, Katarzyna Popłońska, \\ Agnieszka Wojtczak
}

Department of Cytophysiology, University of Lodz, Poland

\begin{abstract}
Lipotubuloids, structures containing lipid bodies and microtubules, are described in ovary epidermal cells of Ornithogalum umbellatum. Microtubules of lipotubuloids can be fixed in electron microscope fixative containing only buffered $\mathrm{OsO}_{4}$ or in glutaraldehyde with $\mathrm{OsO}_{4}$ post-fixation, or in a mixture of $\mathrm{OsO}_{4}$ and glutaraldehyde [1]. None of these substances fixes cortical microtubules of ovary epidermis of this plant which is characterized by dynamic longitudinal growth. However, cortical microtubules can be fixed with cold methanol according immunocytological methods with the use of $\beta$-tubulin antibodies and fluorescein. The existence of cortical microtubules has also been evidenced by EM observations solely after the use of taxol, microtubule stabilizer, and fixation in a glutaraldehyde/OsO $\mathrm{O}_{4}$ mixture. These microtubules mostly lie transversely, sometimes obliquely, and rarely parallel to the cell axis. Staining, using Ruthenium Red and silver hexamine, has revealed that lipotubuloid microtubules surface is covered with polysaccharides. The presumption has been made that the presence of a polysaccharide layer enhances the stability of lipotubuloid microtubules. (Folia Histochemica et Cytobiologica 2011, Vol. 49, No. 2, 285-290)
\end{abstract}

Key words: immunocytochemistry, electron microscopy, taxol, Ruthenium Red, hexamine

\section{Introduction}

Microtubules are polar filaments of a cytoskeleton composed of $\alpha / \beta$ tubulin heterodimers. The cytoskeleton is a complex, dynamic fibrillar net which plays a major role in the generation and regulation of cell architecture and its mechanical features. Moreover, microtubules constitute a scaffold for different biochemical processes. Recent studies have shown that the cytoskeleton is also involved in the spatial organization and regulation of translation [2].

Tubulin may undergo post-translational modulations (PTMs) which result in a functional variety of

Correspondence address: M. Kwiatkowska,

Department of Cytophysiology, University of Lodz,

Pilarskiego Str. 14, 90-231 Lodz, Poland;

tel.: (+ 48 42) 63545 12, fax: (+48 42) 63545 14;

e-mail: kwiat@biol.uni.lodz.pl microtubules. There are many types of PTMs: detyronisation/tyronisation, glutamylation, glycylation, phosphorylation, acetylation, palmitoylation (s-acylation), $\Delta 2$-modification [3-5]. Moreover, microtubule features are modified by microtubule-associated proteins (MAPs). These can be microtubule-stabilizing proteins, microtubule-polymerizing proteins, microtubule-depolymerizing kinesins or microtubulesevering proteins [6].

In a single cell there can be microtubules with different features and stability. In mitotic cells, kinetochor and interpolar microtubules are strongly modified by polyglutamylation, acetylation and detyronisation while astral microtubules are unmodified [7]. Because of this, they exhibit different stability depending on various factors [8]. Neuronal microtubules are the most differentiated; they play an important role in neuronal differentiation-regulation by controlling tubulin availability and modulating microtubule dy- 
namics [3, 6]. In plants it has been observed that some PTMs of $\alpha$ tubulin preferentially appear in a tissue-specific manner [9].

In $O$. umbellatum epidermis cells, specific structures named lipotubuloids can be observed. They mostly consist of osmiophilic granules identified as lipid bodies and microtubules [10]. They are located in the cytoplasmic domain which contains microfilaments, ribosomes, and ER. More rarely, they can also contain mitochondria, Golgi structures, microbodies, and autolytic vacuoles. Lipotubuloids have a rotary-progressive movement and are the site of dynamic lipid synthesis $[1,11,12]$.

Lipotubuloid microtubules are stable: neither low temperature nor short colchicine treatment destroys them. Moreover, they can be fixed only in buffered $\mathrm{OsO}_{4}$, which generally does not preserve other cellular microtubules. In epidermal cells containing easily visible lipotubuloid microtubules, no cortical microtubules can be seen under an electron microscope (EM). These cells grow very dynamically, especially by elongation, and do not divide during ovary development [13]. It would be reasonable to expect strands of microtubules located transversally to the long cell axis which are characteristic of elongating cells [14-17] especially because they are more stable than other microtubules $[18,19]$. Cortical microtubules play an important role in affecting the trajectories of cellulose synthase complex (CSC) in plasma membrane during cell expansion and differentiation $[16,19,20]$. It has been suggested that microtubules, varying in stability, and behaving differently during fixation, may be present in ovary epidermis cells of $O$. umbellatum.

This present study aimed to find out whether there are cortical microtubules in the ovary epidermis of $O$. umbellatum. We aimed to do this using immunocytochemical and EM methods.

\section{Material and methods}

We used ovarian epidermis from fully developed flowers of Ornithogalum umbellatum. The epidermal cells were in the phase of an intense elongation growth and contained a single lipotubuloid, $20-30 \mu \mathrm{m}$ in diameter.

Fluorescent microscopy. Ovarian epidermis of O. umbellatum was fixed according to the protocol outlined by DiDonato and Brasaemle [21] i.e. with cold methanol $\left(-20^{\circ} \mathrm{C}\right)$ for five minutes, then washed four times with cold PBS. Fixed epidermis was incubated in antibody diluent (PBS with $0.1 \mathrm{mg} / \mathrm{ml}$ saponin and $0.5 \mathrm{mg} / \mathrm{ml}$ bovine serum) supplemented with $0.2 \mathrm{M}$ glycine to block nonspecific antibody binding for 45 minutes at room temperature. Next, the tissue sections were squashed onto SuperFrost glass slides. Following freezing with dry ice, coverslips were removed and the slides were incubated with primary mouse monoclonal anti$-\beta$-tubulin antibody clone TUB 2.1 in antibody diluent 1:500 overnight at $4^{\circ} \mathrm{C}$, then adjusted to room temperature, and washed four times (for ten minutes each time) with PBS. Next, the slides were incubated with secondary goat anti-mouse FITC-conjugated antibody in antibody diluent 1:50 for two hours at room temperature in the dark and washed four times for ten minutes each time in PBS. Following washing, slides were air dried and embedded in PBS/glycerol mixture (9:1) with 2.3\% DABCO. Cells were observed using an Optiphot-2 fluorescence microscope (Nikon) equipped with a B-2A filter (blue light; $\lambda=450-490 \mathrm{~nm}$ ) for FITC, and photographed using a DXM 1200 CCD (Nikon) camera.

Electron microscopy. Ovarian epidermis of $O$. umbellatum was preincubated or not preincubated in $15 \mu \mathrm{M}$ taxol at room temperature for two hours and fixed in a mixture of $1 \% \mathrm{OsO}_{4}$ and $2.5 \%$ glutaraldehyde in $0.1 \mathrm{M}$ cacodylate buffer $\left(\mathrm{pH}\right.$ 7.2) for three hours and postfixed in $1 \% \mathrm{OsO}_{4}$ in the same buffer at $4^{\circ} \mathrm{C}$ for three hours. After dehydration in the ethanol series, the material was embedded in a medium consisting of Epon 812 and Spurr's resin. Ultrathin sections $(70 \mathrm{~nm})$, cut using Reichert Joung Ultracut ultra microtome with a glass knife, were double stained with uranyl acetate and lead citrate according to the protocol of Reynolds [22]. The sections were examined and photographed in a JEOL JEM 1010 transmission electron microscope at $80 \mathrm{kV}$ acceleration voltage.

Polysaccharide detection. Silver hexamine staining, according to the technique of Pickett-Heaps [23], and Ruthenium Red staining, according to the technique of Luft [24], were applied in order to detect polysaccharides.

\section{Results}

In ovary epidermal cells, cortical microtubules were not seen in EM images after fixation in the mixture of glutaraldehyde and osmium (Figures 1A, B). But after using the immmunofluorescent technique with $\beta$-tubulin antibodies, they were visible (Figures 1C-E). Cortical microtubules forming delicate strands lay transversely (Figure 1C) or obliquely to the cell long axis (Figure 1D). A very few microtubules running parallel to the cell axis could also be seen (Figure 1E). Moreover, after the use of the immunofluorescent method, the lipotubuloid microtubules were packed so densely in lipotubuloids (Figure 1E) that they formed a bright spot under a standard fluorescent microscope.

When in immunocytochemical pictures cortical microtubules were found in the epidermis, attempts were made to reveal them via electron microscopy using a microtubule stabilizer, namely taxol. Micro- 


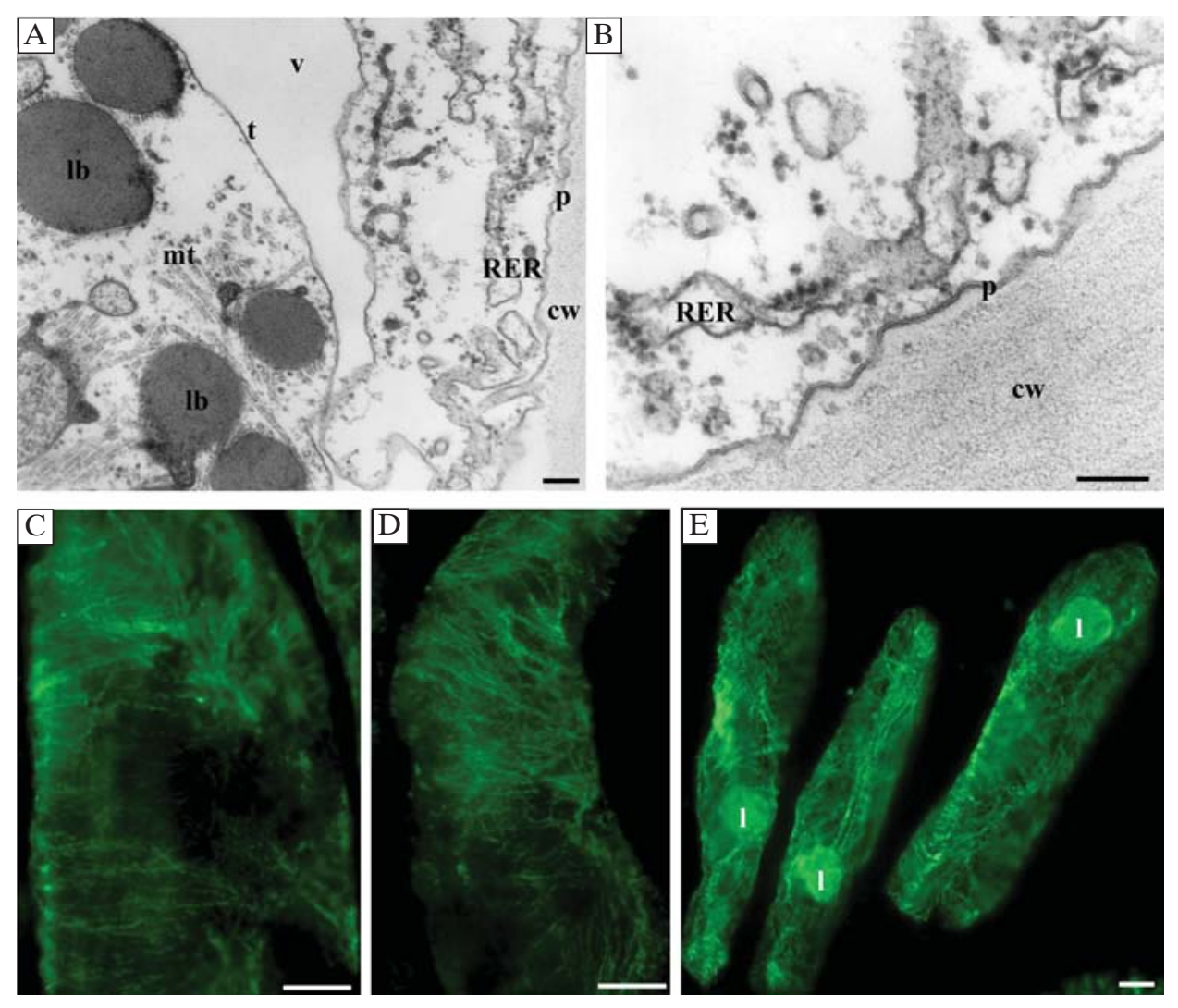

Figure 1. Stable and non-stable microtubules of $O$. umbellatum ovary epidermal cells. Stable microtubules of lipotubuloids (A) and lack of non-stable cortical microtubules (B) in cells not treated with taxol. Cortical microtubules visible in cells fixed with cold methanol (C-E).

$\mathrm{cw}$ - cell wall; 1 - lipotubuloid; lb - lipid body; $\mathrm{mt}$ - microtubules; $\mathrm{p}$ - plasmalemma; RER — rough endoplasmic reticulum; $\mathrm{t}$ - tonoplast; $\mathrm{v}$ - vacuole. Bars for $\mathbf{A}-\mathbf{B}=200 \mathrm{~nm}$, bars for $\mathbf{C}-\mathbf{E}=10 \mu \mathrm{m}$

tubules near the plasmalemma were observed in ovary epidermal cells fixed with a mixture of glutaraldehyde and $\mathrm{OsO}_{4}$ after preincubation with taxol. Microtubules were most often cross-sectioned (Figure 2A) and bound to the plasmalemma by short fibers (Figure 2B). Microtubules oblique to the plasmalemma could also be seen (Figure 2C). A very few microtubules at an acute angle towards the cell wall were visible (Figure 2D). They were parallel to cellulose fibrils situated at the other side of the plasmalemma (Figure 2D). All arrangements of cortical microtubules observed under EM had their counterparts in the images obtained using the immunocytochemical method (compare Figure 1C to Figure 2A, Figure 1B to Figure 1D, and Figures 2C and 1E with Figure 2D).

The presence of polysaccharides on the external surface of lipotubuloid microtubules was revealed using EM/cytochemical methods. Ruthenium Red made lipotubuloid microtubule walls thicker which increased the diameters of whole structures (compare Figure 3A to Figure 3B). The hexamine method according to Pickett-Heaps [23] revealed granular precipitates linearly arranged analogically to mi- crotubules around lipid bodies (compare Figure 3C to Figure 3D). Cortical microtubules were not disclosed by any methods to reveal polysaccharides. This may mean that there are no polysaccharides on their surfaces.

\section{Discussion}

In immunocytochemical observations, we used cold methanol to fix ovary epidermis of $O$. umbellatum [21]. This fixation method is superior to paraformaldehyde fixation for visualization of cortical microtubules that have not been revealed by the classical technique (not shown).

Our immunofluorescent studies showed that in $O$. umbellatum ovary epidermis there were cortical microtubules characteristic of intensively elongating cells. These were mostly transverse. In EM pictures, cortical microtubules (after incubation with taxol) were joined to the plasmalemma by short fibers in a similar way to microtubules in Azolla pinnata [14]. It is thought that connection with the plasmalemma gives them greater stability [19]. But, this was not 

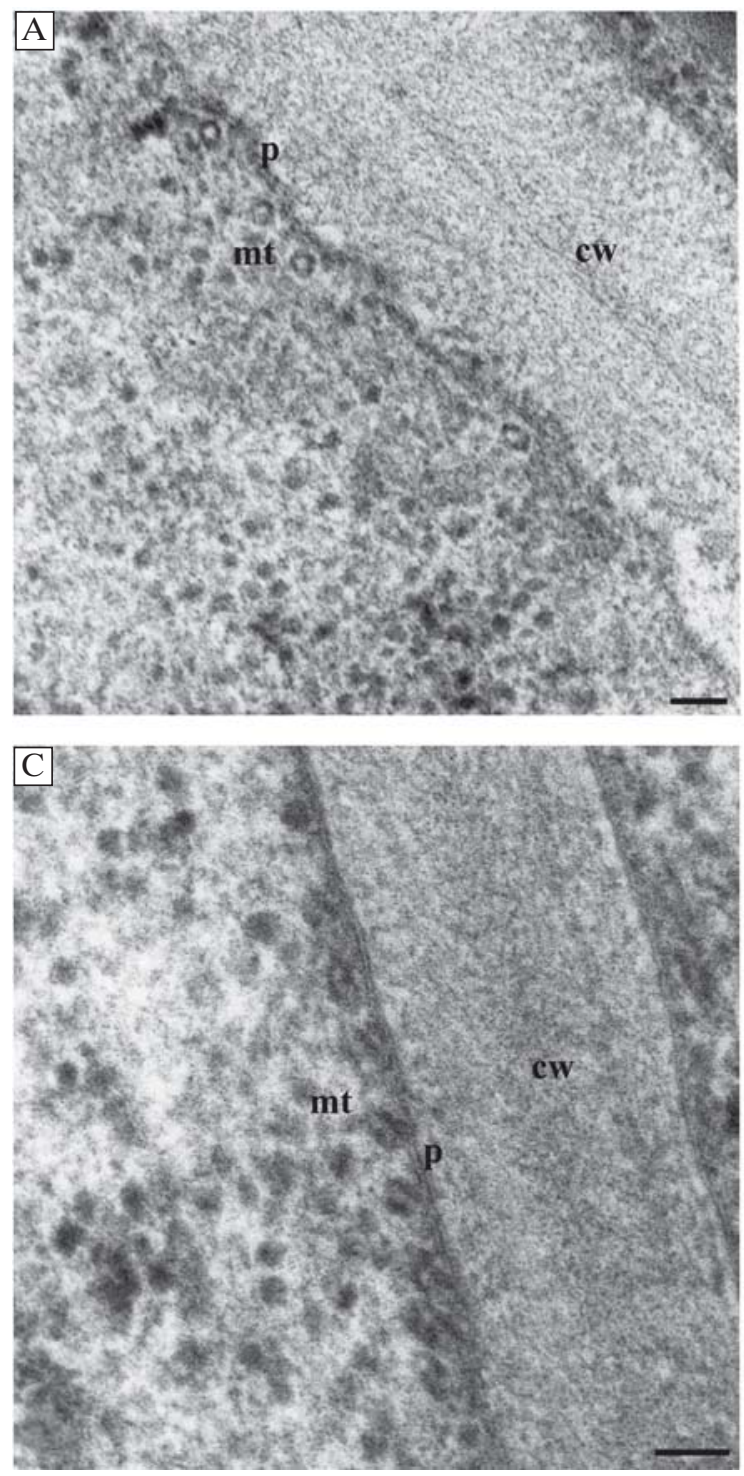
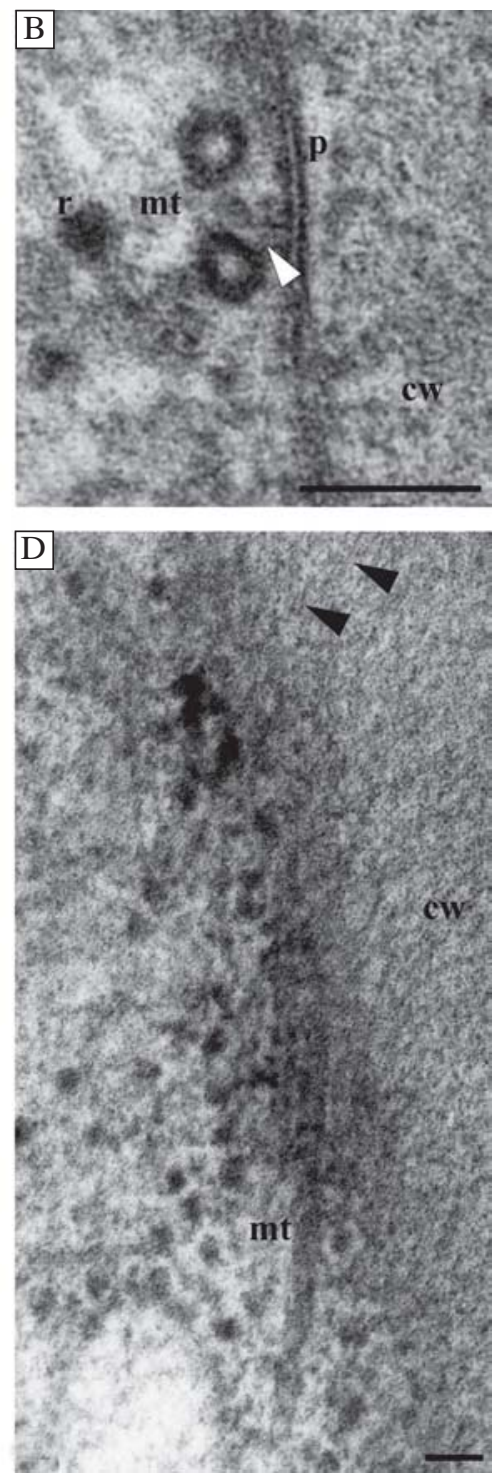

Figure 2. Cortical microtubules of $O$. umbellatum ovary epidermal cells visualized after treatment with taxol. Microtubules in cross-sections (A) bound with plasmalemma with short fibers (white arrow heads) (B), oblique sections (C), and longitudinal sections (D)

$\mathrm{cw}$ - cell wall; $\mathrm{mt}$ - microtubules; $\mathrm{p}$ - plasmalemma; $\mathrm{r}$ - ribosome; black arrow heads - cellulose microfibrils. Bars $=100 \mathrm{~nm}$

observed by us in the case of cortical microtubules in $O$. umbellatum ovary epidermis. They were labile, and only visible under EM after incubation in taxol before fixation.

To the best of our knowledge, this is the first time such a phenomenon has been described in the literature. Taxol induces changes in tubulin conformation, preventing microtubule depolymerization in a very precise way [25]. According to Elie-Caille et al. [26], the formation of straight GDP-tubulin protofilaments in the presence of taxol stabilizes microtubules. It allows for EM visualization of labile cortical microtubules which disintegrate without taxol during fixation with the mixture of glutaraldehyde and osmium. Other authors have shown that taxol can cause tubulin po- lymerization in vitro and in vivo [27]. This may give rise to doubts as to whether microtubules are really present in living cells treated with taxol [28]. This is not the case with $O$. umbellatum ovary epidermal cortical microtubules, the presence of which has also been evidenced by immunocytochemical studies. Their layout was similar to that of cortical microtubules demonstrated by other authors [15].

It is believed that cortical microtubules are a factor controlling the growth of plants $[16,19,20]$. This is probably also true in the case of ovary epidermal cells, something which must be correlated with the complicated process of embryo development and with the morphogenetic process responsible for the formation of a fruit. 

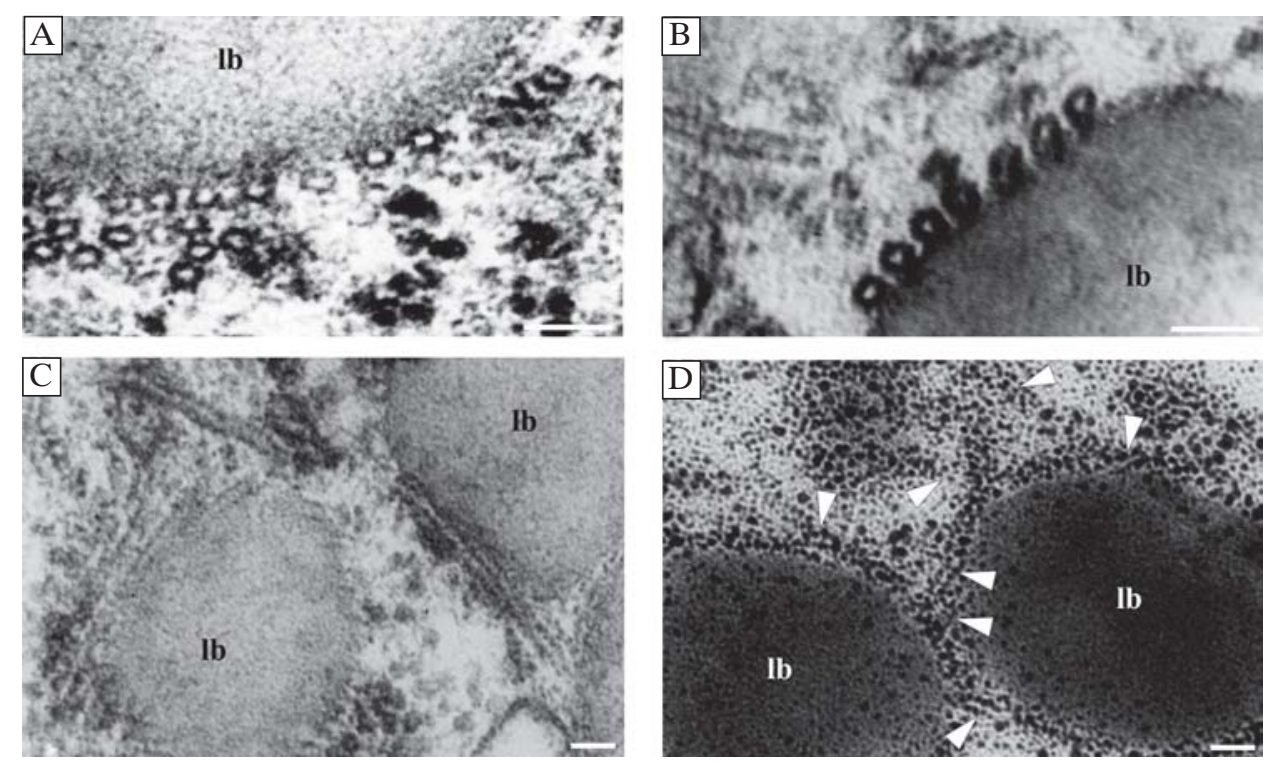

Figure 3. Polysaccharide layer on lipotubuloid microtubules of $O$. umbellatum ovary epidermal cells. Control (A) and Ruthenium Red stained (B) microtubules in cross-sections. Control (C) and silver hexamine-treated (D) microtubules in longitudinal sections (arrow heads). Bars $=100 \mathrm{~nm}$

Varying arrangements of cortical microtubules in different cells may result from the adjustment of the rate of epidermal development to transiently changing dynamics of ovary development. This probably results from the rotation of cortical microtubules [29].

Our cytological observations indicated a specific biochemical modification of lipotubuloid microtubules. The fact that lipotubuloid microtubules were bound with polysaccharides was revealed via the hexamine method according to Pickett-Heaps [23] and the Ruthenium Red method according to Luft [24]. Earlier studies demonstrated that polysaccharides are localized at the outer surface of microtubules. Ruthenium Red makes a microtubule wall thicker by $2.5 \mathrm{~nm}$, and thus its diameter longer by $4.5 \mathrm{~nm}$ [30].

It is reasonable to suppose that the polysaccharide layer at the surface of lipotubuloid microtubules enhances their stability, as is the case with brain nerve cell microtubules which are also coated with the polysaccharide layer revealed by Ruthenium Red staining [31].

It seems probable that a positive reaction to polysaccharides, observed in the case of lipotubuloid microtubules and brain nerve cells, may reflect one form of post-translational modulation.

\section{Acknowledgments}

This work was supported by grant no. 506/820 from the University of Lodz, and was conducted in co-operation with The Scientific Net 'Mechanisms of Cell Motility' MOBILITAS.pl

\section{References}

1. Kwiatkowska M, Popłońska K, Stępiński D. Actin filaments connected with the microtubules of lipotubuloids, cytoplasmic domains rich in lipid bodies and microtubules. Protoplasma. 2005;226:163-167.

2. Kim S, Coulombe PA. Emerging role for the cytoskeleton as an organizer and regulator of translation. Nat Rev Mol Cell Biol. 2010;11:75-81.

3. Fukushima N, Furuta D, Hidaka Y, Moriyama R, Tsujiuchi T. Post-translational modifications of tubulin in the nervous system. J Neurochem. 2009;109:683-693.

4. Ikegami K, Setou M. TTLL10 can perform tubulin glycylation when co-expressed with TTLL8. FEBS Lett. 2009;583: 1957-1963.

5. Etienne-Manneville S. From signaling pathways to microtubule dynamics: the key players. Curr Opin Cell Biol. 2010; 22:104-111.

6. Poulain FE, Sobel A. The microtubule network and neuronal morphogenesis: dynamic and coordinated orchestration through multiple players. Mol Cell Neurosci. 2010;43:15-32.

7. Hammond JW, Cai D, Verhey KJ. Tubulin modifications and their cellular functions. Curr Opin Cell Biol. 2008;20:71-76.

8. Rizk RS, Bohannon KP, Wetzel LA, Powers J, Shaw SL, Walczak CE. MCAK and paclitaxel have differential effects on spindle microtubule organization and dynamics. Mol Biol Cell. 2009;20:1639-1651.

9. Wang W, Vignani R, Scali M, Sensi E, Cresti M. Post-translational modifications of a-tubulin in Zea mays L. are highly tissue specific. Planta. 2004;218:460-465.

10. Kwiatkowska M. Half unit membrane surrounding osmiophilic granules (lipid droplets) of so-called lipotubuloid in Ornithogalum umbellatum. Protoplasma. 1973;77:473-476.

11. Kwiatkowska M. Changes in the diameter of microtubules connected with the autonomous rotary motion of the lipotubuloids (elaioplast). Protoplasma. 1972;75:345-357.

12. Kwiatkowska M, Popłońska K, Stępiński D, Wojtczak A. Lipotubuloids - domains of cytoplasm rich in lipid bodies en- 
twined by microtubule system, active in lipid synthesis. $A d v$ Cell Biol. 2009;DOI: 10.2478/v10052-009-0001-y.

13. Kwiatkowska M, Popłońska K, Kaźmierczak A, Stępiński D, Rogala K, Polewczyk K. Role of DNA endoreduplication, lipotubuloids, and gibberellic acid in epidermal cell growth during fruit development of Ornithogalum umbellatum. J Exp Bot. 2007;58:2023-2031.

14. Hardham AR, Gunning BES. Structure of cortical microtubule arrays in plant cells. J Cell Biol. 1978;77:14-34.

15. Fu Y, Xu T, Zhu L, Wen M, Yang Z. A ROP GTPase signaling pathway controls cortical microtubule ordering and cell expansion in Arabidopsis. Curr Biol. 2009;19:1827-1832.

16. Crowell EF, Gonneau M, Vernhettes S, Höfte H. Regulation of anisotropic cell expansion in higher plants. $C R$ Biol. 2010;333:320-324.

17. Tindemans SH, Hawkins RJ, Mulder BM. Survival of the aligned: ordering of the plant cortical microtubule array. Phys Rev Lett. 2010;104:058103, DOI:10.1103/PhysRevLett.104.058103.

18. Barton DA, Vantard M, Overall RL. Analysis of cortical arrays from Tradescantia virginiana at high resolution reveals discrete microtubule subpopulations and demonstrated that confocal images of arrays can misleading. Plant Cell. 2008; 20:982-994.

19. Szymanski DB, Cosgrove DJ. Dynamic coordination of cytoskeletal and cell wall systems during plant cell morphogenesis. Curr Biol. 2009;19:800-811.

20. Crowell EF, Bischoff V, Desprez T et al. Pausing of Golgi bodies on microtubule regulates secretion of cellulose synthase complexes in Arabidopsis. Plant Cell. 2009;21:1141-1154.

21. DiDonato D, Brasaemle DL. Fixation methods for the study of lipid droplets by immunofluorescence microscopy. $J$ Histochem Cytochem. 2003;51:773-780.
22. Reynolds ES. The use of lead citrate of high $\mathrm{pH}$ as an electron-opaque stain in electron microscopy. J Cell Biol. 1963;17:208-212.

23. Pickett-Heaps JD. Further ultrastructural observations on polysaccharide localization in plant cells. J Cell Sci. 1968; 3:55-64.

24. Luft JH. Ruthenium red staining of the striated muscle cell membrane and the myotendinal junction. In Proc. 6th Int. Cong. For Electron Microscopy. 1966;vol.2 Tokyo, 65-66.

25. Xiao H, Verdier-Pinard P, Fernandez-Fuentes $\mathrm{N}$ et al. Insights into the mechanism of microtubule stabilization Taxol. PNAS. 2006;103:10166-10173.

26. Elie-Caille C, Severin F, Helenius J, Howard J, Muller DJ, Hyman AA. Straight GDP-tubulin protofilaments form in the presence of taxol. Curr Biol. 2007;17:1765-1770.

27. De Brabander M, Geuenes G, Nuydens R, Willebrords R, De Mey J. Taxol induces the assembly of free microtubules in living cells and blocks the organizing capacity of centrosomes and kinetochores. PNAS. 1981;78:5608-5612.

28. Foss M, Wilcox BWL, Alsop GB, Zhang D. Taxol crystals can masquerade as stabilized microtubules. PIoS ONE 2008;3: e1476. doi:10.1371/journal.pone.0001476.

29. Chan J, Sambade A, Calder G, Lloyd C. Arabidopsis cortical microtubules are initiated along, as well as branching from, existing microtubules. Plant Cell. 2009;21:2298-2306.

30. Kwiatkowska M. Polysaccharides connected with microtubules in the lipotubuloids of Ornithogalum umbellatum L. Histochemie. 1973;37:107-112.

31. Tani E, Ametani T. Substructure of microtubules in brain nerve cells as revealed by Ruthenium Red. J Cell Biol. 1970;46:159-165.

Submitted: 16 August, 2010 Accepted after reviews: 4 February, 2011 